\title{
Profiling exercise intensity during the exergame Hollywood Workout on XBOX 360 Kinect $^{\circledR}$
}

\author{
Ricardo B Viana ${ }^{1}$, Rodrigo L Vancini ${ }^{2}$, Carlos A Vieira $^{1}$, Paulo Gentil ${ }^{1}$, Mário H Campos ${ }^{1}$, Marilia S \\ Andrade ${ }^{3}$, Claudio Andre B de Lira ${ }^{\text {Corresp. } 1}$ \\ ${ }^{1}$ Faculdade de Educação Física e Dança, Universidade Federal de Goiás, Goiânia, GO, Brazil \\ 2 Centro de Educação Física e Desportos, Universidade Federal do Espírito Santo, Vitória, ES, Brazil \\ 3 Departamento de Fisiologia, Universidade Federal de São Paulo, São Paulo, SP, Brazil \\ Corresponding Author: Claudio Andre B de Lira \\ Email address: andre.claudio@gmail.com
}

Background: Despite the increasing popularity of exergame practice and its promising benefits in counteracting physical inactivity, limited research has been performed to document the physiological responses during an exergame session. This study aims (i) to investigate the responses of heart rate $(\mathrm{HR})$ and oxygen uptake $\left(\mathrm{VO}_{2}\right)$ during an exergame session and to compare with $\mathrm{HR}$ and $\mathrm{VO}_{2}$ measured during joystick session and (ii) to compare $\mathrm{HR}$ and $\mathrm{VO}_{2}$ obtained during exergame and joystick session with those $\mathrm{HR}$ and $\mathrm{VO}_{2}$ associated with first and second ventilary thresholds (VT1 and VT2, respectively) obtained during a maximal graded exercise test. Methods: Thirty-nine participants performed a maximal graded exercise test to determine maximal oxygen uptake $\left(\mathrm{VO}_{2} \max \right), \mathrm{VT}_{1}$ and $\mathrm{VT}_{2}$. On separate days, participants performed an exergame and traditional sedentary game (with a joystick) sessions. The time that participants remained with $\mathrm{HR}$ and $\mathrm{VO}_{2}$ below the $\mathrm{VT}_{1}$, between the $\mathrm{VT}_{1}$ and $\mathrm{VT}_{2}$ and above the $\mathrm{VT}_{2}$ were calculated to determine exercise intensity. Results: $\mathrm{HR}$ and $\mathrm{VO}_{2}$ were below $\mathrm{VT}_{1}$ during $1503 \pm 292$ seconds $(86.1 \pm 16.7 \%)$ and $1610 \pm 215$ seconds $(92.2 \pm 12.3 \%)$, respectively. There was an increase in $\mathrm{HR}$ and $\mathrm{VO}_{2}$ as a function of exergame phases, since $\mathrm{HR}$ mean values in the 'warm-up' period (119 $\pm 13 \mathrm{bpm})$ were lower than the 'main phase' (136 \pm 15 bpm) and 'cool-down' periods $(143 \pm 15 \mathrm{bpm})(p<0.001)$. Regarding $\mathrm{VO}_{2}$ values, the 'warmup' $\left(25.7 \pm 2.9 \mathrm{~mL} . \mathrm{kg}^{-1} \cdot \mathrm{min}^{-1}\right)$ were similar to the 'main phase' $\left(25.1 \pm 2.8 \mathrm{~mL} \cdot \mathrm{kg}^{-1} \cdot \mathrm{min}^{-1}\right)$

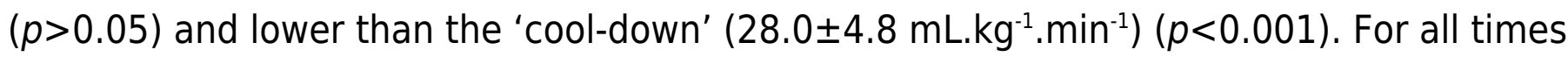
of the joystick session, average $\mathrm{HR}$ and $\mathrm{VO}_{2}$ were below the $\mathrm{VT}_{1}$ levels. Conclusion: Exergames can be classified as light to moderate exercise. Thus, exergames could be an interesting alternative to traditional forms of exercise. 
1 Original Article

2

3 Profiling exercise intensity during the exergame Hollywood Workout on XBOX 360 Kinect $^{\circledR}$ 4

5 Running head: Exercise intensity and exergame

6

7 Ricardo B. Viana ${ }^{1}$, Rodrigo L. Vancini ${ }^{2}$, Carlos A. Vieira ${ }^{1}$, Paulo Gentil ${ }^{1}$, Mário H. Campos ${ }^{1}$, 8 Marília S. Andrade ${ }^{3}$, and Claudio A.B. de Lira ${ }^{1}$

9

$10{ }^{1}$ Laboratório de Avaliação do Movimento Humano, Faculdade de Educação Física e Dança, 11 Universidade Federal de Goiás, Goiânia, Brazil

$12{ }^{2}$ Centro de Educação Física e Desportos, Universidade Federal do Espírito Santo, Vitória, Brazil

13 ³epartamento de Fisiologia, Escola Paulista de Medicina, Universidade Federal de São Paulo, 14 São Paulo, Brazil

15

16 Correspondence to:

17 Claudio Andre Barbosa de Lira

18 E-mail address: andre.claudio@gmail.com 
19 ABSTRACT

20 Background: Despite the increasing popularity of exergame practice and its promising benefits 21 in counteracting physical inactivity, limited research has been performed to document the 22 physiological responses during an exergame session. This study aims (i) to investigate the 23 responses of heart rate $(\mathrm{HR})$ and oxygen uptake $\left(\dot{V} \mathrm{O}_{2}\right)$ during an exergame session and to compare 24 with $\mathrm{HR}$ and $\dot{V} \mathrm{O}_{2}$ measured during joystick session and (ii) to compare $\mathrm{HR}$ and $\dot{V} \mathrm{O}_{2}$ obtained during 25 exergame and joystick session with those $\mathrm{HR}$ and $\dot{V} \mathrm{O}_{2}$ associated with first and second ventilary 26 thresholds (VT1 and VT2, respectively) obtained during a maximal graded exercise test.

27 Methods: Thirty-nine participants performed a maximal graded exercise test to determine 28 maximal oxygen uptake $\left(\dot{\mathrm{V}} \mathrm{O}_{2} \mathrm{max}\right), \mathrm{VT}_{1}$ and $\mathrm{VT}_{2}$. On separate days, participants performed an 29 exergame and traditional sedentary game (with a joystick) sessions. The time that participants 30 remained with $\mathrm{HR}$ and $\dot{V} \mathrm{O}_{2}$ below the $\mathrm{VT}_{1}$, between the $\mathrm{VT}_{1}$ and $\mathrm{VT}_{2}$ and above the $\mathrm{VT}_{2}$ were 31 calculated to determine exercise intensity.

32 Results: $\mathrm{HR}$ and $\dot{\mathrm{V}} \mathrm{O}_{2}$ were below $\mathrm{VT}_{1}$ during $1503 \pm 292$ seconds $(86.1 \pm 16.7 \%)$ and $1610 \pm 215$ 33 seconds $(92.2 \pm 12.3 \%)$, respectively. There was an increase in $\mathrm{HR}$ and $\dot{V} \mathrm{O}_{2}$ as a function of 34 exergame phases, since HR mean values in the 'warm-up' period (119 $\pm 13 \mathrm{bpm})$ were lower than the 'main phase' $(136 \pm 15 \mathrm{bpm})$ and 'cool-down' periods $(143 \pm 15 \mathrm{bpm})(p<0.001)$. Regarding $\dot{V} \mathrm{O}_{2}$ 36 values, the 'warm-up' $\left(25.7 \pm 2.9 \mathrm{~mL} \cdot \mathrm{kg}^{-1} \cdot \mathrm{min}^{-1}\right)$ were similar to the 'main phase' $\left(25.1 \pm 2.8 \mathrm{~mL} . \mathrm{kg}^{-}\right.$ $\left.{ }^{1} \cdot \mathrm{min}^{-1}\right)(p>0.05)$ and lower than the 'cool-down' $\left(28.0 \pm 4.8 \mathrm{~mL} \cdot \mathrm{kg}^{-1} \cdot \mathrm{min}^{-1}\right)(p<0.001)$. For all times of the joystick session, average $\mathrm{HR}$ and $\dot{V} \mathrm{O}_{2}$ were below the $\mathrm{VT}_{1}$ levels.

39 Conclusion: Exergames can be classified as light to moderate exercise. Thus, exergames could be 40 an interesting alternative to traditional forms of exercise. 


\section{INTRODUCTION}

Physical inactivity is associated with an increase in the risk of a variety of chronic diseases (such as diabetes mellitus and arterial hypertension) and consequently, premature deaths (Ding et al., 2016). Although well documented, a large part of the population remains sedentary (Fox, 2012). In this context, adults who are not engaged in traditional exercise methods with a minimum intensity corresponding to $55 \%$ of maximum heart rate (HRmax) require a strategy to achieve and maintain sufficient physical activity for health benefits (Garber et al., 2011).

Exergames, or active videogames, may motivate some adults to engage in physical activity and may be an attractive and fun alternative of physical activity for increasing the motivation of people to engage in an exercise programme (Street, Lacey \& Langdon, 2017).

Exergames can be defined as electronic games that allow players to physically interact with images on screen (Foley \& Maddison, 2010). Traditionally, exergames are characterized as physical activities including games that simulate walking, running, stair climbing, cycling, rowing and swimming (Graves et al., 2010; Wu, Wu \& Chu, 2015). Furthermore, there are games that require mixed activity that simulate jumping, throwing and kicking (Bird et al., 2015).

Most studies involving exergames investigated the acute and chronic effects on caloric expenditure (Barkman et al., 2016), motor aspects (Collado-Mateo et al., 2017), and cognitive function (Garcia et al., 2016; Stanmore et al., 2017) in different healthy and clinical populations (dos Santos Mendes et al., 2012; Collado-Mateo et al., 2017). However, less is known about the physiological responses during an exergame session, especially regarding oxygen uptake $\left(\dot{V} \mathrm{O}_{2}\right)$ and heart rate (HR). These physiological variables are a common form for gathering information about exercise intensity. Moreover, these physiological variables are useful tools to monitor responses and adaptations to exercise. In this regard, it has previously been shown that an increase in one metabolic equivalent ( $1 \mathrm{MET}$ ) in exercise capacity decreases mortality rate by $12 \%$ (Myers et al., 2002; Kodama et al., 2009).

Neves et al.(2015) investigated the acute cardiovascular responses during a session of the game Zumba Fitness Core $^{\circledR}$ performed with XBOX 360 and observed a significant increase immediately after the session. Graves et al.(2010) compared the physiological cost among adolescents, young and older adults during a game with a joystick, Wii ${ }^{\circledR}$ Fit activities (yoga, muscle conditioning, balance and aerobics), and brisk treadmill walking and jogging and found that energy expenditure and HR of $W i i^{\circledR}$ Fit activities were greater than joystick games, but lower than 
73 treadmill exercise and that $\mathrm{Wii}^{\circledR}$ elicited moderate intensity activity. Rodrigues et al.(2015)

74 evaluated the acute metabolic and cardiovascular responses of healthy men during exergames with 75 Nintendo $W_{i i}{ }^{\circledR}$ (obstacle course, hula hoop, free run, soccer heading, penguin slide and table tilt) 76 and found that $W i i^{\circledR}$ exercises are considered to be of light and moderate intensity. Wu et al.(2015) 77 examined and compared the energy expenditure and intensity of XBOX 360 Kinect $^{\circledR}$ exergames $^{-1}$ 78 (boxing, soccer, track and field, ping pong, beach volleyball and bowling) in healthy young adults 79 and observed that boxing and soccer exergames provided the greater exercise intensity. It is 80 important to note that none of these studies determined exercise intensity based on metabolic 81 thresholds obtained in a continuous laboratory treadmill test, such as maximal graded exercise 82 testing (GXT) (de Lira et al., 2013).

83 Thus, despite the increasing popularity of exergame practice (Sween et al., 2014) and its 84 promising benefits in counteracting physical inactivity, limited research has been performed to document the physiological responses during an exergame session, which makes it difficult to characterize the physiological responses and brings uncertainty regarding its potential benefits in increasing physical fitness. Therefore, the aims of this study were to investigate physiological parameters of young men, to describe $\mathrm{HR}$ and $\dot{V} \mathrm{O}_{2}$ responses during the exergame Hollywood Workout on XBOX 360 Kinect session, and to compare with responses in a joystick game. Also, the study compared $\mathrm{HR}$ and $\dot{V} \mathrm{O}_{2}$ responses during exergame with those $\mathrm{HR}$ and $\dot{V} \mathrm{O}_{2}$ associated with VT1 and VT2 attained during a maximal graded exercise test.

The exergame Hollywood Workout on XBOX 360 Kinect was chosen with the intention of maintaining 'ecological validity', as this game simulates some exercises, such as, push-ups, skater lunges and bicycle crunches that are performed in exercise facilities. Also, the study compared HR and $\dot{V} \mathrm{O}_{2}$ responses during this exergame with those of $\mathrm{HR}$ and $\dot{V} \mathrm{O}_{2}$ associated with first and second ventilatory thresholds $\left(\mathrm{VT}_{1}\right.$ and $\left.\mathrm{VT}_{2}\right)$.

\section{MATERIALS AND METHODS}

Participants

Thirty-nine young men were recruited among students from the Faculty of Physical Education and Dance of the Federal University of Goiás (Brazil). Participants (25.9 \pm 4.9 years, $1.79 \pm 0.08 \mathrm{~m}, 79.2 \pm 13.8 \mathrm{~kg}, 24.7 \pm 3.4 \mathrm{~kg} . \mathrm{m}^{-2}$ ) were recruited through social media and direct 
104 participants were informed of the intent, experimental procedures, benefits and risks of the study 105 and informed consent was obtained from all individual participants included in the study. All 106 experimental procedures were approved by the University Human Research Ethics Committee $\left(\mathrm{n}^{\mathbf{0}}\right.$ 107 1.459.010) and conformed to the principles outlined in the Declaration of Helsinki.

\section{Baseline examinations}

Before the beginning of the experiment, each participant came to the laboratory for anamnesis through the Physical Activity Readiness Questionnaire (PAR-Q). The inclusion criteria were to respond 'no' on all the PAR-Q questions. No participants were excluded.

\section{Study design}

Each participant reported to the laboratory on three separate days after baseline 116 examinations. The first day involved baseline examinations and GXT, and the other two days 117 consisted of two randomly ordered sessions (exergame and joystick). The $\mathrm{HR}$ and $\dot{V} \mathrm{O}_{2}$ corresponding to $\mathrm{VT}_{1}$ and $\mathrm{VT}_{2}$ obtained in GXT were used as analysis parameters for the $\mathrm{HR}$ and $\dot{V} \mathrm{O}_{2}$ recorded during the exergame and joystick sessions. All sessions were started at the same time of day with at least 48 hours separating the beginning of each visit. Participants were instructed to eat a standardized meal, not to participate in any strenuous exercise, and not to consume any stimulant or alcohol in the 24 hours preceding all testing sessions. The temperature and relative humidity in the testing laboratory ranged from 21 to $23^{\circ} \mathrm{C}$ and 55 to $65 \%$, respectively, for all

124 trials.

\section{Experimental procedures}

\section{Maximal graded exercise testing}

128 GXT was administrated to determine $\mathrm{VT}_{1}, \mathrm{VT}_{2}$ and maximal oxygen uptake $\left(\dot{\mathrm{V}} \mathrm{O}_{2} \mathrm{max}\right)$, as well as their associated running velocities, $\mathrm{HR}$ and $\dot{V} \mathrm{O}_{2}$. Prior to performing the GXT, participants were given a standardized set of instructions explaining the test. On completion of these preliminary

131 procedures, each participant underwent an incremental maximal exercise test on a motorized 132 treadmill (ATL, Inbramed, Brazil) with 0\% slope. The schedule of this test consisted of a 5-minute 133 warm-up period at $7 \mathrm{~km} \cdot \mathrm{h}^{-1}$, and then the initial speed was progressively increased by $1 \mathrm{~km} \cdot \mathrm{h}^{-1}$ 134 every minute until exhaustion (de Lira et al., 2013). During the exercise testing, participants were 
135 verbally encouraged to exercise for as long as possible. Respiratory gas samples were measured

136 breath by breath using a metabolic system (VO2000, MedGraphics, USA). Prior to testing, the

137 metabolic system was calibrated according to the manufacturer's instructions. HR was recorded

138 using a HR-monitor (Polar Electronics, RS800CX, Finland). Figure 1 shows a participant during 139 the GXT.

140 The following data (averaged over 10 seconds) were obtained: $\dot{V} \mathrm{O}_{2}\left(\mathrm{~mL} \cdot \mathrm{kg}^{-1} \cdot \mathrm{min}^{-1}\right)$ at 141 standard temperature $\left(0^{\circ} \mathrm{C}\right)$ and barometric pressure at sea level, carbon dioxide production $\left(\dot{V} \mathrm{CO}_{2}\right)$

$142\left(\mathrm{~mL} \cdot \mathrm{kg}^{-1} \cdot \mathrm{min}^{-1}\right)$ at standard temperature $\left(0^{\circ} \mathrm{C}\right)$ and barometric pressure at sea level, respiratory 143 exchange ratio (RER), minute ventilation $\left(\dot{V}_{E}\right)\left(\mathrm{L} \cdot \mathrm{min}^{-1}\right)$ at body temperature and saturation 144 pressure, respiratory rate (breaths per minute $[\mathrm{bpm}])$, ventilatory equivalents for $\mathrm{O}_{2}$ and $\mathrm{CO}_{2}\left(\dot{V}_{E} / \dot{V}\right.$

$145 \mathrm{O}_{2}$ and $\dot{V}_{E} / \dot{V} \mathrm{CO}_{2}$, respectively), expired fractions of $\mathrm{O}_{2}$ and $\mathrm{CO}_{2}(\%)$ and $\mathrm{HR}$ (beats per minute $146[\mathrm{bpm}])$. Peak treadmill speed was defined as the last achieved running speed sustained for at least 14730 seconds. $\dot{V} \mathrm{O}_{2}$ max was defined as the highest 10 -second averaged $\dot{V} \mathrm{O}_{2}$ value with inclusion 148 criteria consistent with conventional guidelines for $\dot{V} \mathrm{O}_{2} \max$ (e.g. an inability to sustain the 149 workload, relative $\mathrm{HR}>95 \%$ predicted for their age, RER at maximal exercise $\geq 1.1$, and $\dot{V} \mathrm{O}_{2}$ 150 plateau [the point at which $\dot{V} \mathrm{O}_{2}$ increases less than $150 \mathrm{~mL} \cdot \mathrm{min}^{-1}$ for a given increase in workload]) 151 (Howley, 2007). $\mathrm{VT}_{1}$ and $\mathrm{VT}_{2}$ were assessed using established criteria (Wasserman et al., 2005). 152 Briefly, $\mathrm{VT}_{1}$ corresponds to the break point in the plot of $\dot{V} \mathrm{CO}_{2}$ as a function of $\dot{V} \mathrm{O}_{2}$. At that point, $153 \dot{V}_{E} / \dot{V} \mathrm{O}_{2}$ increases without an increase in $\dot{V}_{E} / \dot{V} \mathrm{CO}_{2} . \mathrm{VT}_{2}$ was located between $\mathrm{VT}_{1}$ and $\dot{V} \mathrm{O}_{2} \mathrm{max}_{\text {, }}$ 154 when $\dot{V}_{E} / \dot{V} \mathrm{CO}_{2}$ starts to increase and $\dot{V}_{E} / \dot{V} \mathrm{O}_{2}$ continues to increase. $\mathrm{VT}_{1}$ and $\mathrm{VT}_{2}$ were determined 155 independently by two experienced investigators. If agreement between the investigators was not 156 achieved, $\mathrm{VT}_{1}$ and $\mathrm{VT}_{2}$ were determined by consensus. To determine the $\dot{V} \mathrm{O}_{2}$ and $\dot{V}_{\mathrm{E}}$ at $\mathrm{VT}_{1}$ and $157 \mathrm{VT}_{2}$, the average of the last 10 seconds of each corresponding level was used. In practical terms, 158 ventilatory thresholds represent points that can be used to classify the intensity of aerobic exercise. 159

\section{Exergame session}

The exergame session was conducted in a room $(10 \mathrm{~m} \times 6 \mathrm{~m})$ and was accompanied by a certified trainer that was experienced in exergames. For the purposes of the present study, the exergame Hollywood Workout (Majesco, USA) was used with the intention of maintaining 'ecological validity', as this game simulates some exercises usually performed in exercise facilities. Indeed, this exergame has several pre-established training protocols consisting of 
166 standardized exercises. Due to the feasibility of performing the exercises by coupling the

167 participant to the metabolic system, the training protocol used in the present study was the Sports 168 Athlete.

169 The Sports Athlete protocol consists of three phases: warm-up, main and cool-down, with 170 a total exercise time of 19 minutes and 28 seconds and total time in transitions between exercises

171 of 8 minutes and 32 seconds, totalling a session of 28 minutes. However, total session time could 172 vary according to the ability of the participant in the transitions between exercises. At the end of 173 the Sports Athlete protocol, a numerical total score was provided. Table 1 provides the exercises 174 used in Sports Athlete protocol.

$175 \quad \mathrm{HR}$ and $\dot{\mathrm{V}} \mathrm{O}_{2}$ were recorded before and during (including rest periods between sets) the 176 Sports Athlete protocol. HR (5 seconds average $\mathrm{HR}$ value) and $\dot{V} \mathrm{O}_{2}\left(10\right.$ seconds average $\dot{V} \mathrm{O}_{2}$ value) 177 registers were monitored by a HR-monitor (Polar Electronics, RS800CX, Finland) and metabolic 178 system (VO2000, MedGraphics, USA), respectively. HR and $\dot{V} \mathrm{O}_{2}$ recorded during the Sports 179 Athlete protocol were compared with $\mathrm{HR}$ and $\dot{\mathrm{V}} \mathrm{O}_{2}$ corresponding to $\mathrm{VT}_{1}$ and $\mathrm{VT}_{2}$ obtained in GXT 180 Figure 2 shows participants performing the Sports Athlete protocol.

181

\section{Joystick session}

183 The participants also underwent a 25-minute joystick game session (traditional sedentary 184 video gaming) (Figure 3). To reduce the effect of playing ability among participants was chosen 185 the joystick-game Injustice: Gods among us, ultimate edition. This game is easy to play and allow 186 the participants restart the fight easily and faster. We tried other joystick-games (fight games) but 187 the participants dispended a lot of time between one fight and other. Indeed, we did not find a 188 joystick-game similar with the exergame Hollywood workout, since it is an exergame which 189 simulates traditional physical exercises. $\mathrm{HR}$ and $\dot{V} \mathrm{O}_{2}$ values were recorded during all time sessions and compared with the $\mathrm{HR}$ and $\dot{V} \mathrm{O}_{2}$ corresponding to $\mathrm{VT}_{1}$ and $\mathrm{VT}_{2}$ obtained in GXT.

191

\section{Statistical analysis}

Age, the highest HR and percent of maximal heart rate (HRmax), and average $\dot{V} \mathrm{O}_{2}$ in the 194 exergame session presented a normal distribution $(p>0.05)$ according to the Shapiro-Wilk tests. 195 All other variables in the exergame and joystick sessions presented a non-normal distribution $(p<$ 196 0.05). Differences between the exergame and joystick sessions were analyzed by the paired 
197 Student $t$-test (data with normal distribution) and Wilcoxon test (data with non-normal 198 distribution). A one way repeated-measures analysis of variance (ANOVA) was used to compare 199 the differences between variables with normal distribution assessed in the 'warm-up', 'main phase' 200 and 'cool-down' periods of the exergame session. When necessary, post hoc testing was performed 201 by multiple comparisons using the Bonferroni procedure for confidence interval correction. The 202 Friedman test was used to compare the differences between variables with non-normal distribution 203 assessed in the 'warm-up', 'main phase' and 'cool-down' periods of the exergame session. The 204 measures of the effect size for bilateral differences were calculated by dividing the mean difference 205 by the standard deviation of the pre-training measurement. The magnitude of the effect sizes was 206 judged according to the following criteria: $d=0.2$ considered a 'small' effect size; 0.5 represented 207 a 'medium' effect size; and 0.8 a 'large' effect size (Cohen, 1988). All statistical analyses were 208 performed with the Statistical Package for the Social Sciences (SPSS) version 20.0. The 209 significance level was set $p<0.05$. Data are shown as the means \pm standard deviations.

\section{RESULTS}

\section{Maximal graded exercise testing}

Data from the GXT are shown in Table 2. $\mathrm{VT}_{1}$ and $\mathrm{VT}_{2}$ were detected in all cases.

\section{Exergame session}

216 HR behaviour during the Sports Athlete protocol is shown in Table 3. The highest HR and $217 \%$ of HRmax attained in both the 'main phase' and 'cool-down' of the exergame session were 218 about $11 \pm 10 \%$, higher than those attained in the 'warm-up' $(p<0.001$ for both, effect size $=1.17$ 2191.30 [large] for all comparisons). The average HR and \% of HRmax attained in the 'cool-down' 220 was $20.4 \pm 11.8 \%$ and $5.2 \pm 7.1 \%$, higher than those attained in the 'warm-up' ( $p<0.001$, effect 221 size $=1.71$ and 1.76 [large], respectively) and 'main phase' ( $p<0.001$, effect size $=0.47$ [small] 222 and 0.51 [medium], respectively), respectively. The average HR and \% of HRmax attained in the 223 'main phase' was about $14.6 \pm 9.7 \%$, higher than that attained in the 'warm-up' $(p<0.001$, effect 224 size $=1.21$ and 1.33 [large], respectively). During the 'warm-up', the average time spent at a HR 225 below the $\mathrm{VT}_{1}$, between the $\mathrm{VT}_{1}$ and $\mathrm{VT}_{2}$, and above the $\mathrm{VT}_{2}$ was $289 \pm 27$ seconds, $10 \pm 25$ 226 seconds and $1 \pm 4$ seconds, respectively. In the 'main phase', the average time spent at a HR below 227 the $\mathrm{VT}_{1}$, between the $\mathrm{VT}_{1}$ and $\mathrm{VT}_{2}$, and above the $\mathrm{VT}_{2}$ was $947 \pm 197$ seconds, $119 \pm 144$ seconds 
228

229

230

231

232

233

234

235

236

237

238

239

240

241

242

243

244

245

246

247

248

249

250

251

252

253

254

255

256

257

258

and $34 \pm 87$ seconds, respectively. During the 'cool-down', the average time spent at a HR below the $\mathrm{VT}_{1}$, between the $\mathrm{VT}_{1}$ and $\mathrm{VT}_{2}$, and above the $\mathrm{VT}_{2}$ was $271 \pm 83$ seconds, $63 \pm 66$ seconds and $14 \pm 41$ seconds.

The $\dot{V} \mathrm{O}_{2}$ behaviour during the Sports Athlete protocol is also shown in Table 3. The highest $\dot{V} \mathrm{O}_{2}$ attained in the 'cool-down' of the Sports Athlete protocol of the exergame Hollywood Workout was $8.8 \pm 15.2 \%$, higher than those attained in the 'main phase' ( $p=0.009$, effect size $=0.54$ [medium]). The highest percent of $\dot{V} \mathrm{O}_{2}$ max attained in the 'cool-down' was $8.8 \pm 15.2 \%$, higher than those attained in the 'main phase' $\left(p=0.009\right.$, effect size $=0.47$ [small]). The average $\dot{V} \mathrm{O}_{2}$ attained in the 'cool-down' was $9.7 \pm 16.9 \%$ and $11.5 \pm 11.1 \%$, higher than those attained in the 'warm-up' ( $p=0.005$, effect size $=0.58$ [medium] $)$ and 'main phase' $(p<0.001$, effect size $=0.74$ [medium]), respectively. The average percent of $\dot{V} \mathrm{O}_{2} \max$ attained in the 'cool-down' was $11.5 \pm$ $11.1 \%$, higher than those attained in "main phase" $(p<0.001$, effect size $=0.36$ [small]), respectively.

As compared with $\dot{V} \mathrm{O}_{2}$ corresponding to $\mathrm{VT}_{1}$ and $\mathrm{VT}_{2}$, in the 'warm-up', the average time spent at a $\dot{V} \mathrm{O}_{2}$ below the $\mathrm{VT}_{1}$, between the $\mathrm{VT}_{1}$ and $\mathrm{VT}_{2}$, and above the $\mathrm{VT}_{2}$ was $271 \pm 44$ seconds, $27 \pm 39$ seconds and $2 \pm 11$ seconds, respectively. In the 'main phase', the average time spent below the $\mathrm{VT}_{1} \dot{V} \mathrm{O}_{2}$, between the $\mathrm{VT}_{1}$ and $\mathrm{VT}_{2}$, and above the $\mathrm{VT}_{2}$ was $1048 \pm 125$ seconds, $45 \pm$ 109 seconds and $6 \pm 37$ seconds, respectively. Finally, in the 'cool-down', the mean time spent below the $\mathrm{VT}_{1} \dot{V} \mathrm{O}_{2}$, between the $\mathrm{VT}_{1}$ and $\mathrm{VT}_{2}$, and above the $\mathrm{VT}_{2}$ was $294 \pm 87$ seconds, $42 \pm 49$ seconds and $14 \pm 43$ seconds, respectively.

Overall, HR and $\dot{V} \mathrm{O}_{2}$ of participants in the exergame session remained on average $1503 \pm$ 292 seconds $(86.1 \pm 16.7 \%$ of the total time session $)$ and $1610 \pm 215$ seconds $(92.2 \pm 12.3 \%$ of the total time session), respectively, below their $\mathrm{VT}_{1}$ values (Table 3 ).

The highest HR and percentage of HRmax in the exergame session were higher $(96.4 \pm$ $29.7 \%$ for both) than in the joystick session $(p<0.001$ for both, effect size $=6.21$ and 6.19 [large], respectively). Additionally, the average HR and percentage of HRmax in the exergame session were higher $(83.1 \pm 39.5$ for both $)$ than in the joystick session $(p<0.0001$, effect size $=5.18$ and 6.37 [large], respectively). Regarding $\dot{V} \mathrm{O}_{2}$, the highest $\dot{V} \mathrm{O}_{2}$ and percentage of $\dot{V} \mathrm{O}_{2} \mathrm{max}$ in the exergame session were four times $(401.4 \pm 120.2 \%$ for both) higher than in the joystick session $(p$ $<0.001$, effect size $=6.64$ and 6.34 [large], respectively). The average $\dot{V} \mathrm{O}_{2}$ and percentage of $\dot{V}$ $\mathrm{O}_{2} \mathrm{max}$ in the exergame session were four times ( $401.7 \pm 84.3 \%$ for both) higher than in the joystick 
259

260

261

262

263

264

265

266

267

268

269

270

271

272

273

274

275

276

277

278

279

280

281

282

283

284

285

286

287

288

289

session $(p<0.001$, effect size $=9.26$ and 6.48 [large], respectively). For all times of the joystick session (25 minutes), average $\mathrm{HR}(73 \pm 9 \mathrm{bpm})$ and $\dot{V} \mathrm{O}_{2}\left(5.3 \pm 1.4 \mathrm{~mL} \cdot \mathrm{kg}^{-1} \cdot \mathrm{min}^{-1}\right)$ were spent below the $\mathrm{VT}_{1}$ levels, corresponding to $35.2 \pm 5.0 \%$ of $\mathrm{HRmax}$ and $8.5 \pm 1.8 \%$ of $\dot{V} \mathrm{O}_{2}$ max of the participants, respectively. The highest $\mathrm{HR}(88 \pm 12 \mathrm{bpm})$ and $\dot{V} \mathrm{O}_{2}$ values $\left(9.2 \pm 3.2 \mathrm{~mL} \cdot \mathrm{kg}^{-1} \cdot \mathrm{min}^{-}\right.$ ${ }^{1}$ ) attained in the joystick session corresponded to $46.2 \pm 6.9 \%$ of HRmax and $14.7 \pm 4.6 \%$ of $\dot{V}$ $\mathrm{O}_{2}$ max of the participants, respectively. All variables in the joystick session presented lower values to the exergame session $(p<0.001)$.

\section{DISCUSSION}

The main aims of the present study were to investigate the responses of $\mathrm{HR}$ and $\dot{V} \mathrm{O}_{2}$ in young men during an exergame session (Hollywood Workout on XBOX 360 Kinect $^{\circledR}$ ) and compare with $\mathrm{HR}$ and $\dot{V} \mathrm{O}_{2}$ measured during joystick session. We also aimed to compare $\mathrm{HR}$ and $\dot{V} \mathrm{O}_{2}$ during the exergame session in relation to $\mathrm{VT}_{1}$ and $\mathrm{VT}_{2}$. As expected, physiological response values during the joystick session were lower than those evaluated during the exergame session. In addition, we found that the average intensity of the Sports Athlete protocol was 'light to moderate', as an appreciable percentage $\left(\sim 86 \%[\mathrm{HR}]\right.$ and $\left.\sim 92 \%\left[\dot{V} \mathrm{O}_{2}\right]\right)$ of the exercise bout occurred at an intensity lower than $\mathrm{HR}$ and $\dot{V} \mathrm{O}_{2}$ in $\mathrm{VT}_{1}$ levels (Stangier et al., 2016). Confirming this finding, the average percentage HRmax and percentage $\dot{V} \mathrm{O}_{2}$ max during the Sports Athlete protocol were $70.7 \%$ and $41.6 \%$, respectively.

These values are similar to data from other studies with exergames (Tan et al., 2002; Unnithan, Houser \& Fernhall, 2006; Jordan, Donne \& Fletcher, 2011) and contrary to other (Neves et al., 2015). Jordan et al.(2011) reported that 15 healthy men (age $29 \pm 4$ years, body mass $81 \pm$ $12 \mathrm{~kg}$, height $1.77 \pm 0.05 \mathrm{~m}$, body mass index $25.9 \pm 3.8 \mathrm{~kg} \cdot \mathrm{m}^{-2}, \dot{V} \mathrm{O}_{2}$ peak $44.8 \pm 5.5 \mathrm{ml} \cdot \mathrm{kg}^{-1} \cdot \mathrm{min}^{-1}$ ) attained $\sim 66 \%$ and $\sim 72 \%$ of HRmax and $\sim 41 \%$ and $\sim 56 \%$ of $\dot{V} \mathrm{O}_{2}$ max during $W i{ }^{\circledR}$ boxing and an exergame controlled only with movements of the lower limbs through PlayStation ${ }^{\circledR} 2$. Tan et al.(2002) reported that 40 young individuals (21 men and 19 women, age $17.5 \pm 0.7$ years) attained an average $\mathrm{HR}$ of $137 \mathrm{bpm}$ (70\% of HRmax), average $\dot{V} \mathrm{O}_{2}$ of $24.6 \mathrm{~mL} \cdot \mathrm{kg}^{-1} \cdot \mathrm{min}^{-1}\left(44 \%\right.$ of $\left.\mathrm{VO}_{2} \max \right)$ during the exergame Dance Dance Revolution $3^{\text {rd }}$ Mix $^{\mathrm{TM}}$ Konami ${ }^{\circledR}$. Unnithan et al.(2006) reported that children and adolescents (11-17 years) attained 65\% of HRmax during the exergame Dance Dance Revolution ${ }^{\mathrm{TM}}$ Konami $^{\circledR}$. On the other hand, average $\dot{V} \mathrm{O}_{2}\left(\sim 35 \%\right.$ of $\dot{V} \mathrm{O}_{2}$ peak $)$ did not reach the minimum values for development and maintenance of cardiorespiratory fitness $(>46 \%$ of $\dot{V}$ 
$290 \mathrm{O}_{2} \mathrm{max}$ ) proposed by the American College of Sports Medicine (ACSM) (Garber et al., 2011), 291 similar to the results of the present study. Mills et al.(2013) and Lau et al.(2015) found similar 292 results to the present study regarding percentage of HRmax in children during a high-intensity 293 exergame (Kinect Sports-200 m Hurdles) and the exergame I-Dong running, respectively; 294 however, the percentage of $\dot{V} \mathrm{O}_{2}$ max reported by Mills et al.(2013) and Lau et al.(2015) was, 295 respectively, lower $(40.3 \%)$ and higher $(61.4 \%)$ than that found in the present study. In general, 296 despite previous studies investigating different populations and exercises, our results are in line 297 with the literature. However, it is important to emphasize that the presented data should be 298 extrapolated with caution.

299 According to the ACSM criteria, the intensity of the Sports Athlete protocol of the 300 exergame Hollywood Workout can be classified as moderate, since it elicited average HR values 301 corresponding to $70.7 \%$ of HRmax, framed in the range of 64-76\% of HRmax proposed by the 302 ACSM (Garber et al., 2011). The moderate intensity of the Sports Athlete protocol can be justified 303 by fact that the evaluated participants presented high cardiorespiratory fitness, demanding a lower $304 \mathrm{HR}$ and $\dot{V} \mathrm{O}_{2}$ for the same workload when compared to sedentary individuals (DeMaria et al., 305 1978). In addition, the ACSM suggests that exercise must have a minimum intensity corresponding 306 to $55 \%$ of HRmax to evoke the benefits of aerobic training (Garber et al., 2011). Therefore, the 307 Sports Athlete protocol of the exergame Hollywood Workout can be a useful tool for improving 308 cardiorespiratory fitness as well as being an alternative tool to traditional exercise protocols. 309 However, it should be noted that for this purpose, the weekly exercise volume of at least 150 310 minutes (which would correspond to five exercise sessions, considering that each Sports Athlete 311 protocol lasts approximately 30 minutes) must be met. An important advantage of the Sports 312 Athlete protocol compared to classic aerobic activities (e.g. running, cycling) is that this protocol 313 has exercises for both lower and upper limbs, thus being a training protocol for the whole body, 314 which can increase $\dot{V}_{\mathrm{E}}, \mathrm{HR}$ and $\dot{V} \mathrm{O}_{2}$ values to exercise through a greater amount of muscle mass 315 involved (Jensen-Urstad, Svedenhag \& Sahlin, 1994).

316 When evaluating the protocol in phases, significant differences were found between 317 average HR of the 'warm-up' and the 'main phase'. As desired, the intensity of the 'warm-up' 318 period was lower than the intensity of the 'main phase', which follows the recommendations for 319 exercise prescription (Powers \& Howley, 2017). This is a very important aspect, since the 'warm320 up' may be related to the reduction of the probability of muscular injuries due to stretches or 
321 dislocations (Woods, Bishop \& Jones, 2007) in addition to influencing subsequent physical 322 (Fradkin, Zazryn, \& Smoliga, 2010) and muscular performance (Mascarin et al., 2015). On the 323 other hand, a significant increase of the HR and $\dot{V} \mathrm{O}_{2}$ occurred at the end of the 'cool-down'. This 324 is contrary to the recommendations for exercise prescription (Pescatello et al., 2014; Powers \& 325 Howley, 2017), since the 'cool-down' should provide a gradual decrease of the HR (Powers \& 326 Howley, 2017). A possible explanation for the 'cool-down' intensity remaining high may be 327 related to the Mountain Climbers exercise present in the 'cool-down' period, since the participants 328 arrived very close to the 'maximum effort' (reported by participants), reflecting the amount of 329 repetitions performed both in this exercise as in the others that constituted the 'cool-down'.

330

\section{Strengths and limitations of the study}

332

To the best of our knowledge, this is the first study to evaluate the intensity of an exergame

333 through the $\mathrm{HR}$ and $\dot{V} \mathrm{O}_{2}$ values at $\mathrm{VT}_{1}$ and $\mathrm{VT}_{2}$ obtained from GXT. Most studies evaluated the intensity of exergames through percentages of the HRmax recommended by ACSM. The Sports Athlete protocol consists of exercises that people usually perform in their traditional routine of training (e.g. jog, bicycle crunches, push-ups, jump rope ...), thus our results can be extrapolated to exercise facilities/gyms.

On the other hand, the participants in the present study performed all sessions coupled to the mouthpiece of the metabolic system. The discomfort generated by the salivation and fatigue of the chewing muscles (reported by the participants) may have interfered in the performance of the participants, although the performance of participants was better than suggested by the exergame.

342 Thus, studies evaluating the influence of using the mouthpiece or mask over performance in exergames are needed, besides the accomplishment of the Sports Athlete protocol of the exergame Hollywood Workout in a non-laboratory context. Indeed, the study population included in this study were physically active. Therefore, future studies with sedentary individuals are needing to confirm our finding and understand the transferability of this findings to sedentary populations.

347 Furthermore, the use of this protocol in the long term may be important to confirm the hypothesis

348 that it would improve musculoskeletal and cardiorespiratory fitness, as well as possible changes 349 in body composition as a function of energy expenditure. Blood lactate assessment could 350 contribute to information on metabolic stress and anaerobic pathway contributions, since many 351 participants reported high peripheral muscle fatigue. Nevertheless, we believe that these 
352 limitations do not prevent the conclusions of the study to be drawn.

353

354 CONCLUSIONS

355 From the present data, it appears that the exergames used in the present study can be 356 classified as light to moderate physical exercise for the participants evaluated. Indeed, during the 357 exergames trial, $\dot{V} \mathrm{O}_{2}$ and $\mathrm{HR}$ remained predominantly below the $\mathrm{VT}_{1}$ level previously assessed 358 during the GXT. Confirming this finding, the average $\dot{V} \mathrm{O}_{2}$ and $\mathrm{HR}$ during the exergames were 359 according to ACSM's recommendations. Thus, exergames could be an interesting alternative to traditional forms of exercise as a tool for increasing physical fitness.

361

362

\section{ACKNOWLEDGEMENTS}

363

We would like to thank the participants for their effort and commitment to the research 364 project.

\section{REFERENCES}

Barkman J., Pfeiffer K., Diltz A., Peng W. 2016. Examining energy expenditure in youth using XBOX kinect: Differences by player mode. Journal of Physical Activity and Health 13:S41-S43. DOI: 10.1123/jpah.2016-0016.

Bird M-L., Clark B., Millar J., Whetton S., Smith S. 2015. Exposure to "exergames" increases older adults' perception of the usefulness of technology for improving health and physical activity: A pilot study. JMIR Serious Games 3:e8. DOI: 10.2196/games.4275.

de Lira CAB., Peixinho-Pena LF., Vancini RL., de Freitas Guina Fachina RJ., de Almeida AA., Andrade MDS., da Silva AC. 2013. Heart rate response during a simulated olympic boxing match is predominantly above ventilatory threshold 2: A cross sectional study. Open Access Journal of Sports Medicine 4:175-82. DOI: 10.2147/OAJSM.S44807. 
383 DeMaria AN., Neumann A., Lee G., Fowler W., Mason DT. 1978. Alterations in ventricular

384

385

386

387

388

389

390

391

392

393

394

395

396

397

398

399

400

401

402

403

404

405

406

407

408

409

410

411

412

413 mass and performance induced by exercise training in man evaluated by echocardiography. Circulation 57:237-44.

Ding D., Lawson KD., Kolbe-Alexander TL., Finkelstein EA., Katzmarzyk PT., van Mechelen W., Pratt M. 2016. The economic burden of physical inactivity: a global analysis of major non-communicable diseases. The Lancet 388:1311-1324. DOI: 10.1016/S01406736(16)30383-X.

Foley L., Maddison R. 2010. Use of active video games to increase physical activity in children: a (virtual) reality? Pediatric Exercise Science 22:7-20.

Fox M. 2012. What is sedentarism? Journal of the Academy of Nutrition and Dietetics 112:1124. DOI: $10.1016 / j$.jand.2012.06.018.

Fradkin AJ., Zazryn TR., Smoliga JM. 2010. Effects of warming-up on physical performance: A systematic review with meta-analysis. Journal of Strength and Conditioning Research 24:140-148. DOI: 10.1519/JSC.0b013e3181c643a0.

Garber CE., Blissmer B., Deschenes MR., Franklin BA., Lamonte MJ., Lee I-M., Nieman DC., Swain DP. 2011. Quantity and quality of exercise for developing and maintaining cardiorespiratory, musculoskeletal, and neuromotor fitness in apparently healthy adults. Medicine \& Science in Sports \& Exercise 43:1334-1359.

Garcia JA., Schoene D., Lord SR., Delbaere K., Valenzuela T., Navarro KF. 2016. A bespoke kinect stepping exergame for improving Physical and cognitive function in older people: A pilot study. Games for Health Journal 5:382-388. DOI: 10.1089/g4h.2016.0070.

Graves LE., Ridgers ND., Williams K., Stratton G., Atkinson G., Cable NT. 2010. The physiological cost and enjoyment of Wii Fit in adolescents, young adults, and older adults. Journal of Physical Activity \& Health 7:393-401.

Howley ET. 2007. VO2max and the plateau-needed or not? Medicine and Science in Sports and Exercise 39:101-2. DOI: 10.1249/mss.0b013e31802dc897.

Jensen-Urstad M., Svedenhag J., Sahlin K. 1994. Effect of muscle mass on lactate formation during exercise in humans. European Journal of Applied Physiology and Occupational Physiology 69:189-95.

Jordan M., Donne B., Fletcher D. 2011. Only lower limb controlled interactive computer gaming enables an effective increase in energy expenditure. European Journal of Applied 

Physiology 111:1465-1472. DOI: 10.1007/s00421-010-1773-3.

415 Kodama S., Saito K., Tanaka S., Maki M., Yachi Y., Asumi M., Sugawara A., Totsuka K., 416 Shimano H., Ohashi Y., Yamada N., Sone H. 2009. Cardiorespiratory fitness as a 417 quantitative predictor of all-cause mortality and cardiovascular events in healthy men and women. JAMA 301:2024. DOI: 10.1001/jama.2009.681.

Lau PWC., Liang Y., Lau EY., Choi C-R., Kim C-G., Shin M-S. 2015. Evaluating physical and perceptual responses to exergames in Chinese children. International journal of environmental research and public health 12:4018-30. DOI: 10.3390/ijerph120404018.

Mascarin NC., Vancini RL., Lira CAB., Andrade MS. 2015. Stretch-Induced Reductions in Throwing Performance Are Attenuated by Warm-up Before Exercise. Journal of Strength and Conditioning Research 29:1393-1398. DOI: 10.1519/JSC.0000000000000752.

Mills A., Rosenberg M., Stratton G., Carter HH., Spence AL., Pugh CJA., Green DJ., Naylor 163:806-810. DOI: 10.1016/j.jpeds.2013.03.076.

Myers J., Prakash M., Froelicher V., Do D., Partington S., Atwood JE. 2002. Exercise Capacity and Mortality among Men Referred for Exercise Testing. New England Journal of Medicine 346:793-801. DOI: 10.1056/NEJMoa011858.

Neves LEDS., Cerávolo MPDS., Silva E., De Freitas WZ., Da Silva FF., Higino WP., Carvalho WRG., De Souza RA. 2015. Cardiovascular effects of Zumba® performed in a virtual environment using XBOX Kinect. Journal of Physical Therapy Science 27:2863-5. DOI: 10.1589/jpts.27.2863.

Pescatello LS., Arena A., Riebe D., Thompson PD. 2014. ACSM's guidelines for exercise testing and prescription. Philadelphia: Wolters Kluwer/Lippincott Williams \& Wilkins Health.

Powers SK., Howley ET. 2017. Exercise physiology: Theory and application to fitness and performance. New York: McGraw-Hill Education.

Rodrigues GAA., Felipe DDS., Silva E., De Freitas WZ., Higino WP., Da Silva FF., De Carvalho WRG., Aparecido de Souza R. 2015. Acute cardiovascular responses while playing virtual games simulated by Nintendo Wii ${ }^{\circledR}$. Journal of Physical Therapy Science 27:2849-2851. DOI: 10.1589/jpts.27.2849.

dos Santos Mendes FA., Pompeu JE., Modenesi Lobo A., Guedes da Silva K., Oliveira T de P., Peterson Zomignani A., Pimentel Piemonte ME. 2012. Motor learning, retention and 
445

446

447

448

449

450

451

452

453

454

455

456

457

458

459

460

461

462

463

464

465

466

467

468

469

470

471

472

473

474

475

transfer after virtual-reality-based training in Parkinson's disease--effect of motor and cognitive demands of games: a longitudinal, controlled clinical study. Physiotherapy 98:217-23. DOI: 10.1016/j.physio.2012.06.001.

Stangier C., Abel T., Mierau J., Hollmann W., Strüder HK. 2016. Cardiorespiratory demands during an inline speed skating marathon race: a case report. The Journal of Sports Medicine and Physical Fitness 56:1007-12.

Stanmore E., Stubbs B., Vancampfort D., de Bruin ED., Firth J. 2017. The effect of active video games on cognitive functioning in clinical and non-clinical populations: A meta-analysis of randomized controlled trials. Neuroscience \& Biobehavioral Reviews 78:34-43. DOI: 10.1016/j.neubiorev.2017.04.011.

Street TD., Lacey SJ., Langdon RR. 2017. Gaming Your Way to Health: A Systematic Review of Exergaming Programs to Increase Health and Exercise Behaviors in Adults. Games for Health Journal 6:136-146. DOI: 10.1089/g4h.2016.0102.

Sween J., Wallington SF., Sheppard V., Taylor T., Llanos AA., Adams-Campbell LL. 2014. The role of exergaming in improving physical activity: a review. Journal of Physical Activity \& Health 11:864-70. DOI: 10.1123/jpah.2011-0425.

Tan B., Aziz AR., Chua K., Teh KC. 2002. Aerobic demands of the dance simulation game. International Journal of Sports Medicine 23:125-9. DOI: 10.1055/s-2002-20132.

Unnithan V., Houser W., Fernhall B. 2006. Evaluation of the Energy Cost of Playing a Dance Simulation Video Game in Overweight and Non-Overweight Children and Adolescents. International Journal of Sports Medicine 27:804-809. DOI: 10.1055/s-2005-872964.

Wasserman K., Hansen J., Sue D., Stringer W., Whipp B. 2005. Principles of exercise testing and interpretation. Philadelphia: Lippincott Williams \& Wilkins.

Woods K., Bishop P., Jones E. 2007. Warm-up and stretching in the prevention of muscular injury. Sports Medicine 37:1089-99.

Wu PT., Wu WL., Chu IH. 2015. Energy expenditure and intensity in healthy young adults during exergaming. American Journal of Health Behavior 39:557-561. DOI:

10.5993/AJHB.39.4.12.

\section{FIGURE LEGENDS}

Figure 1. Maximal graded exercise testing session. 
476 Figure 2. Some exercises of the Sports Athlete protocol performed by the participants during the 477 exergame session. $\mathrm{A}=$ Skater Lunges; $\mathrm{B}=\mathrm{Jog} ; \mathrm{C}=$ Jump Rope; $\mathrm{D}=$ Push-ups.

478 Figure 3. Joystick session.

479

480 TABLE LEGENDS

481 Table 1. Sports Athlete Protocol of the exergame Hollywood Workout.

482 Table 2. Physiological variables obtained by maximal graded exercise testing.

483 Table 3. Heart rate, oxygen uptake and time (expressed as relative percentages) in each metabolic 484 zone, defined as below $\mathrm{VT}_{1}$, between the $\mathrm{VT}_{1}$ and $\mathrm{VT}_{2}$, and above the $\mathrm{VT}_{2}$ during each phase of 485 the exergame session $(n=39)$. 


\section{Table $\mathbf{1}$ (on next page)}

Sports Athlete Protocol of the exergame Hollywood Workout.

*Repetitions proposed by the exergame. However, the participant was instructed to perform as many repetitions as possible. 
1 Table 1. Sports Athlete Protocol of the exergame Hollywood Workout.

\begin{tabular}{|c|c|c|c|c|}
\hline Phases & Exercises & Sets & Time (seconds) & Repetitions* \\
\hline \multirow{4}{*}{ Warm-up } & Jog & 1 & 71 & 25 \\
\hline & Trunk Crosses & 1 & 62 & 20 \\
\hline & Jumping Jacks & 1 & 68 & 40 \\
\hline & Ice Skaters & 1 & 59 & 12 \\
\hline \multirow{9}{*}{ Main } & Push-ups & 1 & 59 & 12 \\
\hline & Skater Lunges & 1 & 69 & 16 \\
\hline & Bicycle Crunches & 1 & 74 & 25 \\
\hline & Push-ups & 1 & 73 & 15 \\
\hline & Skater Lunges & 1 & 82 & 24 \\
\hline & Bicycle Crunches & 1 & 74 & 25 \\
\hline & Push-ups & 1 & 74 & 15 \\
\hline & Skater Lunges & 1 & 81 & 24 \\
\hline & Bicycle Crunches & 1 & 74 & 25 \\
\hline \multirow{4}{*}{ Cool-down } & Punches & 1 & 61 & 25 \\
\hline & Jump Rope & 1 & 56 & 40 \\
\hline & Side Shuffles & 1 & 68 & 20 \\
\hline & Mountain Climbers & 1 & 63 & 25 \\
\hline
\end{tabular}

2 *Repetitions proposed by the exergame. However, the participant was instructed to perform as 3 many repetitions as possible. 


\section{Table 2 (on next page)}

Physiological variables obtained by maximal graded exercise testing.

Data are presented as the means \pm standard deviation. GXT: maximal graded exercise test. $\mathrm{VO}_{2}$ : oxygen uptake. $\mathrm{VO}_{2}$ max: maximal oxygen uptake. HR: heart rate. HRmax: maximal heart rate. $\mathrm{VT}_{1}$ : first ventilatory threshold. $\mathrm{VT}_{2}$ : second ventilatory threshold. bpm: beats per minute. N/A: not applicable. 
1 Table 2. Physiological variables obtained by maximal graded exercise testing.

\begin{tabular}{ccccrc}
\hline GXT $(\mathrm{n}=39)$ & $\begin{array}{c}\dot{\mathrm{V}} \mathrm{O}_{2} \\
\left(\mathrm{~mL} \cdot \mathrm{kg}^{-1} \cdot \mathrm{min}^{-1}\right)\end{array}$ & $\% \dot{\mathrm{V}} \mathrm{O}_{2} \max$ & $\begin{array}{c}\mathrm{HR} \\
(\mathrm{bpm})\end{array}$ & $\begin{array}{c}\text { \% attained HRmax } \\
\left(\mathrm{km}^{-1}\right)\end{array}$ & $\begin{array}{c}\text { Speed } \\
\mathrm{VT}_{1}\end{array}$ \\
$38.1 \pm 5.9$ & $60.9 \pm 6.3$ & $156 \pm 12$ & $82.0 \pm 4.9$ & $10.6 \pm 1.2$ \\
$\mathrm{VT}_{2}$ & $48.7 \pm 6.3$ & $77.7 \pm 5.7$ & $172 \pm 10$ & $90.2 \pm 3.7$ & $13.2 \pm 1.4$ \\
Maximal exercise & $62.7 \pm 7.4$ & N/A & $191 \pm 11$ & N/A & $16.1 \pm 1.7$
\end{tabular}

2 Data are presented as the means \pm standard deviation. GXT: maximal graded exercise test. $\dot{V} \mathrm{O}_{2}$ :

3 oxygen uptake. $\dot{V} \mathrm{O}_{2}$ max: maximal oxygen uptake. HR: heart rate. HRmax: maximal heart rate.

$4 \mathrm{VT}_{1}$ : first ventilatory threshold. $\mathrm{VT}_{2}$ : second ventilatory threshold. bpm: beats per minute. N/A:

5 not applicable. 


\section{Table 3(on next page)}

Heart rate, oxygen uptake and time (expressed as relative percentages) in each metabolic zone

Heart rate, oxygen uptake and time (expressed as relative percentages) in each metabolic zone, defined as below $\mathrm{VT}_{1}$, between the $\mathrm{VT}_{1}$ and $\mathrm{VT}_{2}$, and above the $\mathrm{VT}_{2}$ during each phase of the exergame session $(n=$ 39).

Note: Data are presented as the means \pm standard deviation. Abbreviations: bpm: beats per minute; HR: heart rate; $\mathrm{HRmax}$ : maximum heart rate; $\mathrm{N} / \mathrm{A}$ : not applicable; $\mathrm{VO}_{2}$, oxygen uptake; $\mathrm{VT}_{1}$ : first ventilatory threshold; $\mathrm{VT}_{2}$ : second ventilatory threshold. *significant difference from 'warm-up'. " significant difference from 'main phase'. 
1 Table 3. Heart rate, oxygen uptake and time (expressed as relative percentages) in each metabolic zone, defined as below $\mathrm{VT}_{1}$,

2 between the $\mathrm{VT}_{1}$ and $\mathrm{VT}_{2}$, and above the $\mathrm{VT}_{2}$ during each phase of the exergame session $(n=39)$.

\begin{tabular}{|c|c|c|c|c|}
\hline & Warm-up & Main phase & Cool-down & $p$ \\
\hline \multicolumn{5}{|c|}{ HR } \\
\hline Highest HR (bpm) & $149 \pm 12$ & $165 \pm 15^{*}$ & $164 \pm 13^{*}$ & $<.001$ \\
\hline$\%$ attained HRmax & $78.5 \pm 6.3$ & $86.5 \pm 6.4^{*}$ & $86.4 \pm 7.2 *$ & $<.001$ \\
\hline Average HR (bpm) & $119 \pm 13$ & $136 \pm 15^{\#}$ & $143 \pm 15^{* \#}$ & $<.001$ \\
\hline$\%$ attained HRmax & $62.6 \pm 6.7$ & $71.4 \pm 6.5^{\#}$ & $74.9 \pm 7.3^{* \#}$ & $<.001$ \\
\hline Time below to $\mathrm{HR}$ at $\mathrm{VT}_{1}(\%)$ & $96.5 \pm 9.0$ & $86.1 \pm 17.9^{*}$ & $78.4 \pm 24.1^{*}$ & $<.001$ \\
\hline Time between to $\mathrm{HR}$ at $\mathrm{VT}_{1}-\mathrm{VT}_{2}(\%)$ & $3.3 \pm 8.0$ & $10.8 \pm 13.1^{*}$ & $18.3 \pm 19.2^{*}$ & $<.001$ \\
\hline Time above to $\mathrm{HR}$ at $\mathrm{VT}_{2}(\%)$ & $0.2 \pm 1.3$ & $3.1 \pm 7.9^{*}$ & $3.2 \pm 9.8$ & .015 \\
\hline \multicolumn{5}{|c|}{$\dot{V} \mathbf{O}_{2}$} \\
\hline Highest $\dot{V} \mathrm{O}_{2}\left(\mathrm{~mL} \cdot \mathrm{kg}^{-1} \cdot \mathrm{min}^{-1}\right)$ & $38.5 \pm 4.5$ & $38.3 \pm 4.9$ & $41.7 \pm 7.5^{\#}$ & .009 \\
\hline$\%$ attained $\dot{V} \mathrm{O}_{2} \max$ & $62.0 \pm 8.9$ & $61.7 \pm 9.0$ & $66.9 \pm 12.7^{\#}$ & .009 \\
\hline Average $\dot{V} \mathrm{O}_{2}\left(\mathrm{~mL} \cdot \mathrm{kg}^{-1} \cdot \mathrm{min}^{-1}\right)$ & $25.7 \pm 2.9$ & $25.1 \pm 2.8$ & $28.0 \pm 4.8^{* \#}$ & $<.001$ \\
\hline$\%$ attained $\dot{V} \mathrm{O}_{2} \max$ & $41.5 \pm 7.2$ & $40.5 \pm 6.9$ & $45.3 \pm 9.4^{\#}$ & $<.001$ \\
\hline Time below to $\dot{V} \mathrm{O}_{2}$ at $\mathrm{VT}_{1}(\%)$ & $90.2 \pm 14.7$ & $95.3 \pm 11.3^{*}$ & $84.0 \pm 20.7^{\#}$ & .001 \\
\hline Time between to $\dot{V} \mathrm{O}_{2}$ at $\mathrm{VT}_{1}-\mathrm{VT}_{2}(\%)$ & $9.0 \pm 13.0$ & $4.1 \pm 10.0$ & $12.0 \pm 14.1^{\#}$ & .024 \\
\hline Time above to $\dot{V} \mathrm{O}_{2}$ at $\mathrm{VT}_{2}(\%)$ & $0.8 \pm 3.8$ & $0.6 \pm 3.4$ & $4.0 \pm 11.8$ & .010 \\
\hline
\end{tabular}

3 Note: Data are presented as the means \pm standard deviation. Abbreviations: bpm: beats per minute; HR: heart rate; HRmax: maximum

4 heart rate; N/A: not applicable; $\dot{V} \mathrm{O}_{2}$, oxygen uptake; $\mathrm{VT}_{1}$ : first ventilatory threshold; $\mathrm{VT}_{2}$ : second ventilatory threshold. * significant

5 difference from 'warm-up'. " significant difference from 'main phase'. 
Figure 1

Maximal graded exercise testing session.

Photo credit: Ricardo B. Viana. 


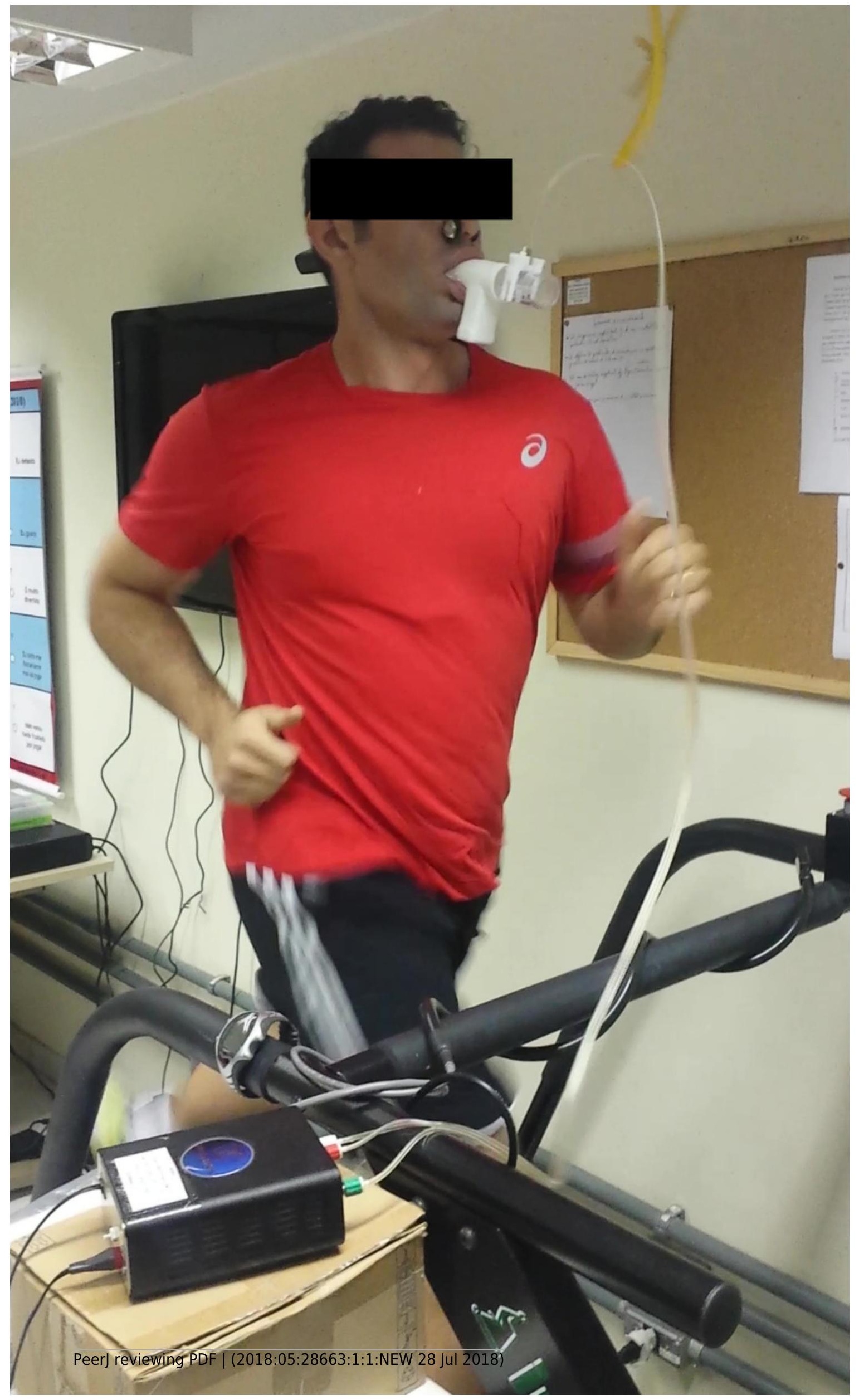




\section{Figure 2}

Some exercises of the Sports Athlete protocol performed by the participants during the exergame session.

$A=$ Skater Lunges; $B=$ Jog; $C=$ Jump Rope; $D=$ Push-ups.

Photo credit: Ricardo B. Viana.

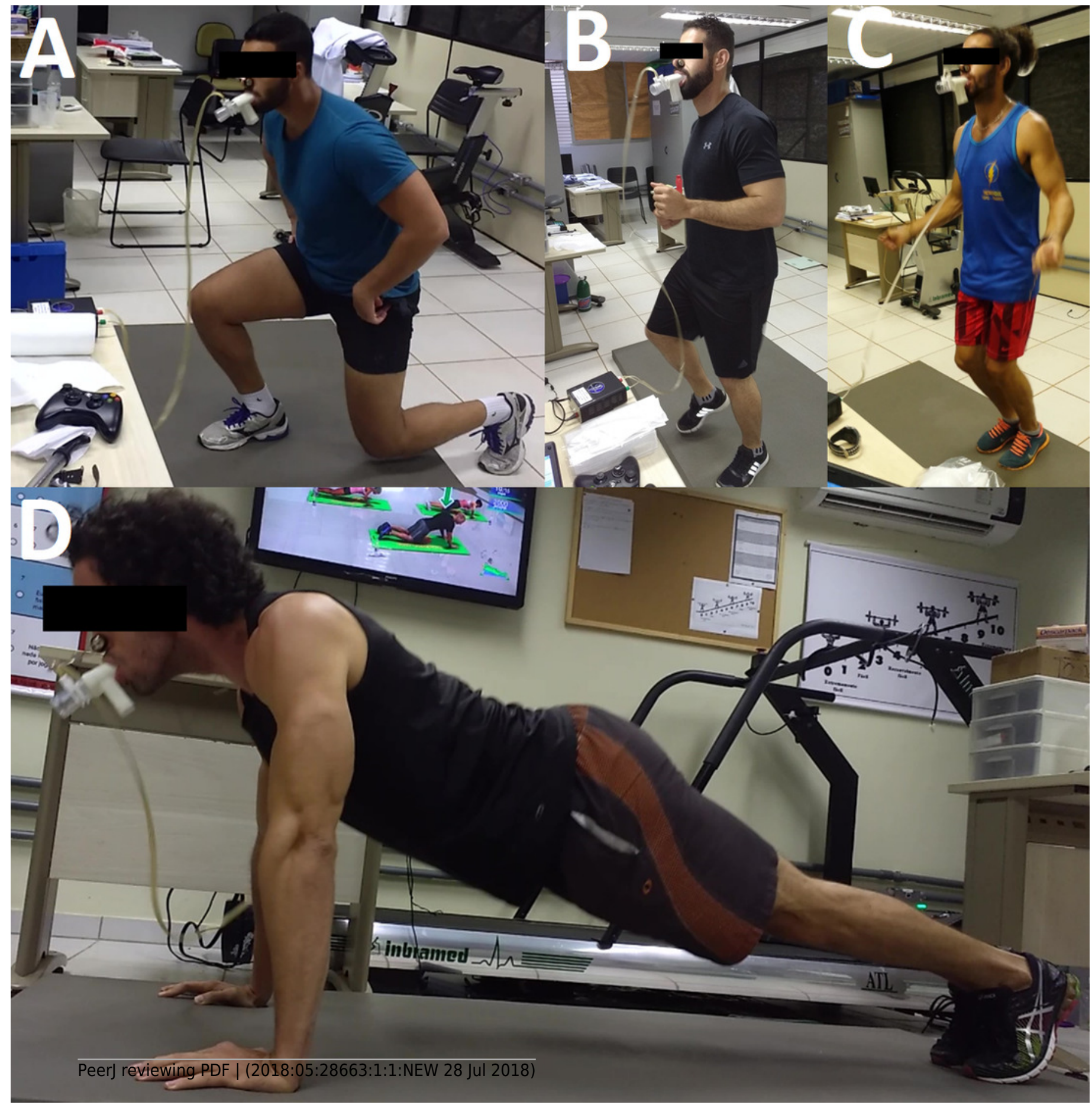


Figure 3

Joystick session.

Photo credit: Ricardo B. Viana.

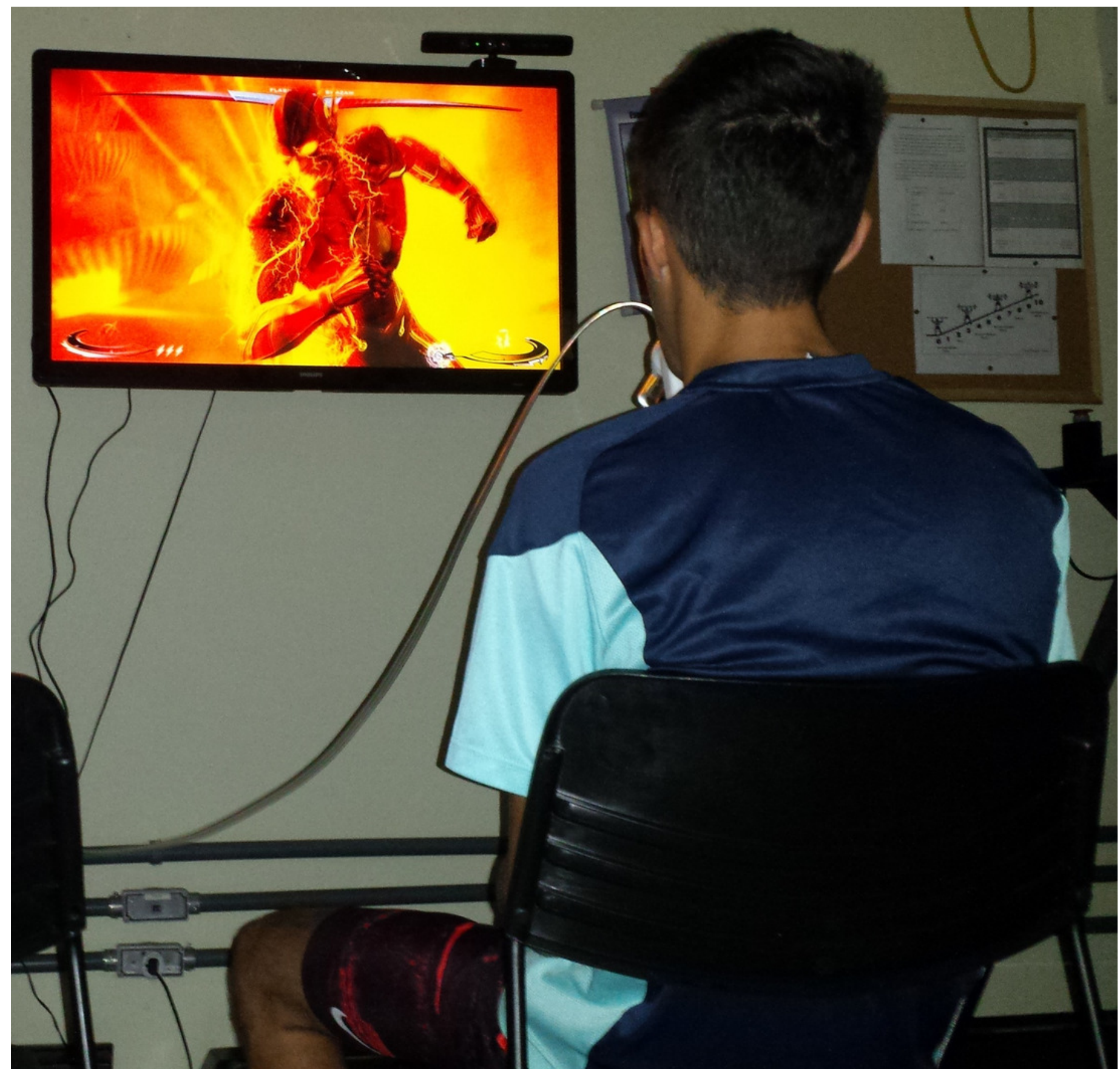

